\title{
Gene flow in Plantago. II. Gene flow pattern and population structure. A simulation study*
}

\author{
Marten Bos and \\ Egbert van der Haring
}

\author{
Department of Genetics, Centre of Biological \\ Sciences, University of Groningen, Kerklaan 30, \\ 9751 NN Haren. The Netherlands.
}

The relative effects of the pattern of pollen flow, pattern of seed dispersal, presence or absence of a selfincompatibility system and annual versus perennial life cycle on hosiozygosity and the evolution of population structure in a plant species were studied using computer simulation. Starting with a random distribution of genotypes at a diallelic marker locus in populations of 2500 individuals, simulations were run for the equivalent of 100 or 400 years. Sixteen different situations were investigated, one of which corresponded to a species like Plantago lanceolata: a perennial herb with restricted seed dispersal, a gametophytic self-incompatibility system and a protogyny-growth syndrome. Regression analysis of fixation index values $(F)$ showed that the presence of the protogyny-growth syndrome or self-incompatibility lowered the increase of homozygosity, while restricted seed dispersal and perenniality promoted inbreeding. Analysis of population structure demonstrated that the "patchiness" of a population after 100 generations was higher in a perennial species than in an annual, while the pollen flow pattern caused by the presence of the protogyny syndrome reduced the development of population structure.

It appears that genetic structure within populations of a species like $P$. lanceolata can still be explained by restricted gene flow, in spite of the presence of outcrossing mechanisms like self-incompatibility and protogyny.

\section{INTRODUCTION}

When gene flow between (sub)populations is extensive, it may reduce the diversifying effect of selection (Wright, 1951; Antonovics, 1968; Endler, 1973; Gillespie, 1975) or drift (Wright, 1951; Moran, 1962; Kimura and Weiss, 1964; Weiss and Kimura, 1965; Nei et al., 1977; Roughgarden, 1979). With restricted gene flow, genetic divergence may occur among different areas within a population as a result of drift (Wright, 1968; Rohlf and Schnell, 1971; Turner et al., 1982; Crawford, 1984) or selection (Jain and Bradshaw, 1966; Bradshaw, 1972; Christiansen, 1975; Gillespie, 1975; Levin and Wilson, 1978).

Measurements of "realized" gene flow (resulting in seed) in synthetic or natural plant populations by the use of genetic markers are rare. Most measurements come from crop populations (e.g., Handel, 1982, 1983; Levin, 1984; Levin and Kerster, 1974), some from natural species or situations (e.g., Schaal, 1975, 1980; Levin, 1981; Ennos and Clegg, 1982; Bos et al., 1985; Ennos, 1985). These gene flow measurements in crops and herbs show

\footnotetext{
* Grassland Species Research Group Publication No. 136.
}

mainly restricted flow. The opinions about the importance of gene flow as an evolutionary force are diverse, culminating in a remark of Ellstrand and Marshall (1985): "Within a species alone, the importance (of gene flow)... may range from trivial to critical".

The genetic variability of plant characters which influence the amount of gene flow between populations within a species, and which therefore may be of importance for the speed of evolution, is not well documented. Moreover, the characters are often not recognized as gene flow characters and therefore not described as such.

Van Dijk (1987) presents "the mean gene transport per generation" $M=\sqrt{ } \frac{1}{2} \pi\left(\sigma_{s}^{2}+\frac{1}{2} t \sigma_{p}^{2}\right)$ as a measurement of gene flow. Therefore, characters influencing the amount of outcrossing $(t)$, seed $(s)$ and pollen $(p)$ dispersal variances are gene flow characters. We will demonstrate this with some characters: clone size, mating system characteristics, and flowering height.

In self-incompatible species the probability of a pollen grain being effective changes with clone size. As clone size increases pollination distance may expand. There is also an increase in the 
dispersal variance of flowers from the plant base ( $\sigma_{v}^{2}=$ variance of vegetative growth) and therefore neighbourhood area and size increase (Gliddon $e t$ al., 1987). In selfing species the situation would be different (Levin and Kerster, 1971). Therefore, populations can evolve local differentiation as a result of restricted gene flow caused by clone size changes.

A mating system characteristic like distyly in Primula vulgaris or Linum tenuifolium can have large consequences for the outcrossing rate (Calahan and Gliddon, 1985; Nicholls, 1985) and consequently for gene flow distances. While increased gene flow can result in reduced inbreeding depression, there may be an optimal outcrossing distance beyond which the disruption of locally adaptive combinations of genes creates outbreeding depression (Price and Waser, 1979; Waddington, 1983). We give this example together with Nicholls' (1985) remarks that it becomes necessary to reconsider distyly as an outcrossing device.

Schmitt et al. (1985) suggest that if environmental heterogeneity is an important factor in the evolution of breeding systems, differential dispersal of selfed and outcrossed progeny may be a widespread phenomenon in plants with mixed mating systems. Seeds from the explosively dehiscent chasmogamous and cleistogamous flowers of Impatiens capensis are dispersed differently: the larger outcrossed chasmogamous seeds are dispersed farther than the selfed cleistogamous seeds and may reach environments different from that of the maternal parent. Changes in the ratio of selfed and outcrossed progeny result in a change in gene flow: a seed derived from selfing carries two genomes from the female partner, but only one when outcrossed.

In our study of gene flow in the self-incompatible species Plantago lanceolata we discovered that the phenomenon of protogyny is combined with strong growth of the scapes during flowering. This results in what we have called the protogynygrowth syndrome: spikes function as males at a height level far above the level at which they flower as females (Bos et al., 1985). This syndrome influences the pollen flow pattern drastically.

We demonstrate two effects of this changed pollen flow pattern: the influence on the amount of inbreeding (fixation index $F$ ) and on the structuring of populations. These effects are shown in sixteen simulations in combination with the effects of three other variable characteristics: seed dispersal, presence or absence of a self-incompatibility (SI) system and turnover-rate (replacement per year).

\section{GENE FLOW CHARACTERISTICS OF THE MODEL}

The anemophilous species Plantago lanceolata L. exhibits a gametophytic self-incompatibility (SI) system, which is thought to be a primitive characteristic of angiosperms (Arasu, 1968). Protogyny, also present in this species, is often considered as a property that increases cross pollination, but seems here to be a superfluous character considering the presence of an SI system. Several hypotheses for the occurrence of protogyny in $P$. lanceolata are given in Bos et al. (1985); see also Lloyd and Webb (1986). The combination of protogyny and continued elongation of the spike through growth (protogyny growth syndrome) results in the pollen being released at a higher level in the vegetation than the level at which the receptive stigmas are present. In this way the syndrome effects the size of the gene flow. The dispersal of a pollen cloud can be described with models developed for the dispersal of a smoke cloud by "eddy diffusion" (Sutton, 1953). Dilution of the pollen cloud by eddies is regarded as a major factor controlling the deposition gradient. Sutton's formula is also discussed in Levin and Kerster (1974). The following formula describes the pollen density $(p)$ at a distance " $x$ " from the pollen source and with a height difference " $z$ " between the centre of the pollen cloud and the receptive stigma.

$$
\begin{aligned}
X_{p}(x, z) & =\frac{Q_{0}}{u \cdot \pi \cdot C_{y} \cdot C_{z} \cdot x^{2-n}} \cdot \exp \left(-\frac{z^{2}}{C_{z} \cdot x^{2-n}}\right) \\
z & =z_{\text {source }}-\frac{v}{u} \cdot x-z_{\text {receptor }}
\end{aligned}
$$

where $Q_{0}=$ pollen density in source $(=1) ; u=$ wind velocity $(\mathrm{m} / \mathrm{s}) ; v=$ terminal velocity of pollen grains $(\mathrm{cm} / \mathrm{s}) ; C_{y}, C_{z}=$ horizontal and vertical diffusion coefficients $\left(C_{y}=0.21\right.$ and $C_{z}=0.12$ in average meteorological conditions according to Tsukado, 1982); $n=$ dimensionless number between zero (high turbulence) and 1 (low turbulence), related to diffusion power of turbulence ( $n=0.25$ under average conditions). As further conditions we used $u=100 \mathrm{~cm} / \mathrm{s}$ and $v=2.5 \mathrm{~cm} / \mathrm{s}$ (usual for particles with pollen diameter).

The relative contributions of male flowering spikes to the pollen pool is assumed to be reflected in the pollen received by local female flowering spikes.

Fig. 1(a) can be constructed using the Sutton formula. Applying the formula in the situations with the protogyny-growth syndrome $(p=1)$ or without the syndrome $(p=0)$ yielded the two curves in Fig. 1(a): the non-leptokurtic curve and 


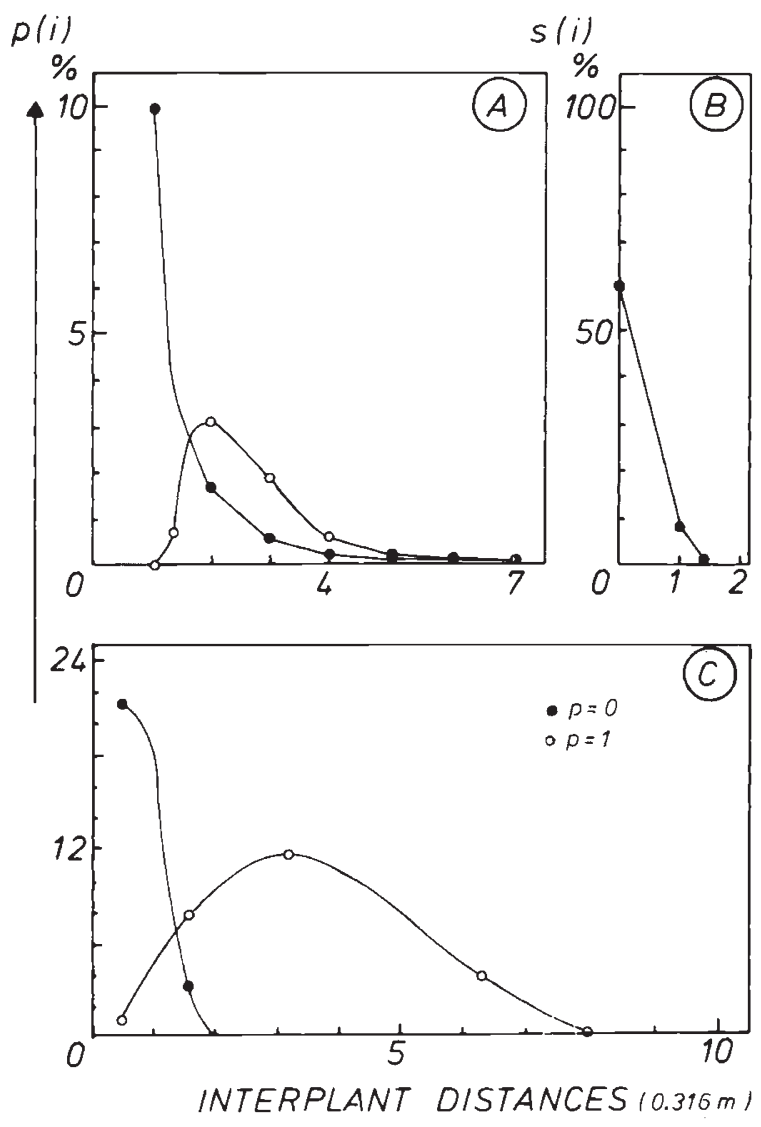

Figure 1 (a) Pollen flow pattern after Sutton (1953) with protogyny-growth syndrome $(p=1)$ and without syndrome $(p=0) . p(i)$ is the probability that a male flowering plant (i) fertilizes a female plant at varying interplant distances. (b) Seed flow pattern (see text). (c) Pollen flow pattern in a wind tunnel (after Bos et al., 1986). Release height of the pollen was always $0.40 \mathrm{~m}$; female recapture height was either the same: $0.40 \mathrm{~m}$ (no syndrome; $p=0$ ) or $0.20 \mathrm{~m}$ (with syndrome; $p=1$ ). $p=0 ; 0-\bigcirc p=1$.

the leptokurtic curve. The assumed height difference between female and male flowering $(0.20 \mathrm{~m})$ stems from observations in the field (Bos et al., 1985). Experiments in a wind tunnel with release and recapture of pollen on the same or at a lower level showed comparable pollen flow patterns (Bos et al., 1986). These patterns are presented in fig. $1(\mathrm{c})$. In the computer simulations we used the patterns of fig. 1(a). For a complete understanding of the gene flow, figures on seed dispersal are needed. Fig. 1(b) shows the seed flow pattern used in the simulations. The dispersal distribution is considered to be normal with a standard deviation $\sigma_{s}=\frac{1}{2}$ interplant distance $=0.168 \mathrm{~m}$ (see next section and Bos et al., 1986, table 6). The seed dispersal equation is:

$$
C(r)=C_{0} \exp \left(-\frac{r^{2}}{\sigma_{s}^{2}}\right)
$$

where $r=$ distance from source; $C_{0}=$ concentration at distance 0 .

The chance of a plant being replaced by seed of a plant (i) is determined by the position of that plant in the probability distribution for seed dispersal: $s(i)=C(r)$.

\section{THE MODEL}

We were mainly interested in the effect of this type of gene flow on local differentiation and genetic structure of a population. Furthermore, the effects of and interactions with the SI-system and annual versus perennial life cycles were considered.

A computer program was written to simulate a large $\left(250 \mathrm{~m}^{2}\right)$, uniformly distributed population of 2500 diploid plants on a square grid of $50 \times 50$ positions. Assuming a density of 10 plants $/ \mathrm{m}^{2}$ resulted in a minimum distance of $0.316 \mathrm{~m}$ between the plants (=interplant distance). The genetic system consisted of a single marker locus with two alleles and a gametophytic self-incompatibility system with a maximum number of 250 SI-alleles in the populations, initially present in equal frequencies $(p=1 / 250)$. Initial marker allele frequencies were $0 \cdot 5$. Selection, migration and mutation were assumed to be absent. A flowchart of the program is presented in fig. 2 .

Pollen donors were selected for each female parent according to the probability distribution equal to one of the two pollen flow patterns in fig. 1(a), which depended as argued before on the presence or absence of the protogyny-growth syndrome. A random direction was used in picking a male parent. When pollination was prohibited by a selfincompatibility reaction another male parent was selected. When all plants had formed a zygote the next "year" was started. For an annual species the total population was replaced by its offspring (turnover rate $=100$ per cent), in case of a perennial species randomly selected plants were replaced (turnover rate $=25$ per cent). Seed could be used in one of two ways: plants were either replaced by their own offspring or seeds were dispersed according to the normal distribution shown in fig. 1(b).

The four variable characteristics (each with two "states") pollen flow pattern $(p)$, presence or absence of the SI-system $(S I)$, seed dispersal $(s)$ and turnover rate $(t)$ yielded a total number of 16 

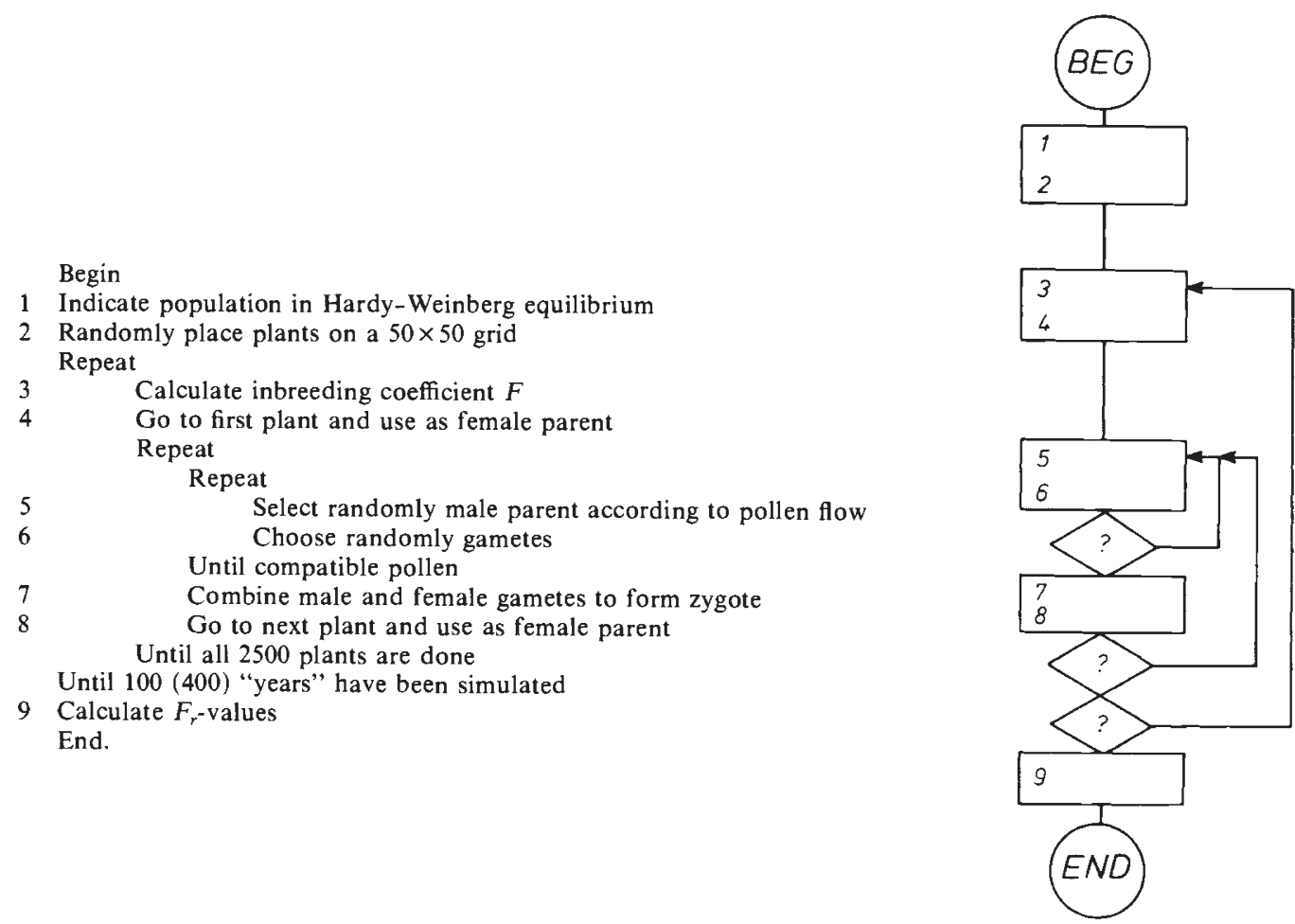

Figure 2 Flow chart and pseudo-code of the simulation program, written in 280 assembly language.

possible situations (table 1). Situation 1 is e.g., a perennial, self-compatible species without seed dispersal and protogyny syndrome (no height difference between the male and female flowering). Situation 15 is the situation of our model species Plantago lanceolata, a perennial, self-incompatible species with restricted seed dispersal and with the protogyny syndrome height difference. Every situation was simulated in ten replicate populations for 100 "years" (annual species) or for 400 "years" (perennial species).

The fixation index (a kind of coefficient of inbreeding) $F$ was calculated each "year" for the marker locus as the proportional loss of heterozygosity from Hardy-Weinberg expectation. Calculated values of $F$ are exact since all individuals in the population are used. At the end of the simulation period $F_{r}$ values ( $F$ at plant distance $r$ ) were calculated as an analogue to $F$ to show the loss of heterozygosity in distance classes (Van Dijk, 1987). $F_{r}$ is a measure of genetic similarity between a plant and individuals at distance $R$. The $F_{r}$ values can therefore be used as a "patchiness index" comparable to Turner's index (Turner et al., 1982) since it is a measure of the genetic similarity between neighbouring plants.

Table 1 Simulated situations. Pollen flow pattern $p=$ leptokurtic (0) or non-leptokurtic (1); seed dispersal $s=$ no seed dispersal $(0)$ or restricted (1);SI-system absent (0) or present (1); turnover rate $t=25$ per cent or 100 per cent. Situation $15=$ Plantago lanceolata

\begin{tabular}{llllrllllr}
\hline Situation & $p$ & $s$ & $S I$ & \multicolumn{1}{c}{$t$} & Situation & $p$ & $s$ & $S I$ & \multicolumn{1}{c}{$t$} \\
\hline 1 & 0 & 0 & 0 & $25 \%$ & 9 & 1 & 0 & 0 & $25 \%$ \\
2 & 0 & 0 & 0 & $100 \%$ & 10 & 1 & 0 & 0 & $100 \%$ \\
3 & 0 & 1 & 0 & $25 \%$ & 11 & 1 & 1 & 0 & $25 \%$ \\
4 & 0 & 1 & 0 & $100 \%$ & 12 & 1 & 1 & 0 & $100 \%$ \\
5 & 0 & 0 & 1 & $25 \%$ & 13 & 1 & 0 & 1 & $25 \%$ \\
6 & 0 & 0 & 1 & $100 \%$ & 14 & 1 & 0 & 1 & $100 \%$ \\
7 & 0 & 1 & 1 & $25 \%$ & 15 & 1 & 1 & 1 & $25 \%$ \\
8 & 0 & 1 & 1 & $100 \%$ & 16 & 1 & 1 & 1 & $100 \%$ \\
\hline
\end{tabular}




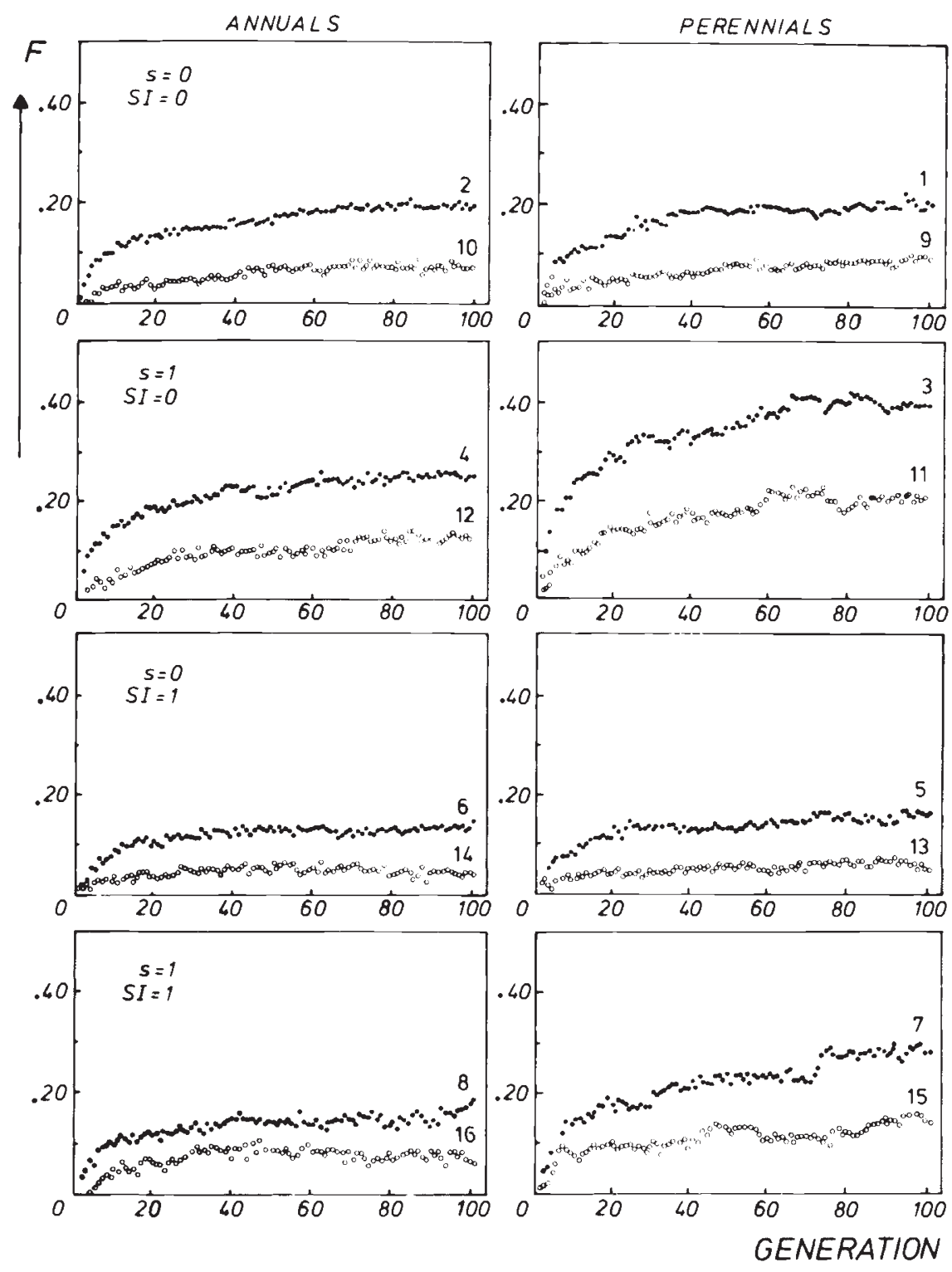

Figure 3 The course of the fixation index $(F)$ in 100 generations of simulation in sixteen different situations, effected by e.g., changed pollen pattern. (-O) protogyny syndrome absent; $\bigcirc \ldots$ syndrome present. Ciphers $1-16$ indicate situations $1-16$ (see table 1 ). The values of $F$ represent averages from 10 replicate simulations.

\section{RESULTS}

After a relatively short period of approximately 50 generations in all simulations the fixation index $(F)$ reached a more or less stable level (fig. 3). F averaged over the last ten generations was used as the value characteristic for a particular situation. These values were used in a multiple regression analysis to reveal the relative effects of the variables on the $F$-value in a population (table 2). Each variable has a significant first-order effect on the inbreeding $(F$-value): the protogyny-growth syndrome $(p)$ and the SI-system $(S I)$ lowered the inbreeding ( $\beta$ is negative), while a seed dispersal $(s)$ greater than zero and a turnover rate $(t)$ of 25 per cent promoted inbreeding ( $\beta$ is positive). The $\beta$-coefficients show that the effect of the presence of the syndrome in these simulations clearly exceeded the effects of the other variables $(\beta=$ $-0.6169)$. All second-order interactions except for 
Table 2 Regression analysis showing the influence and the significance of the independent variables and their interactions on the fixation index $F(n=160) ; \beta$-coefficient $=$ standard partial correlation. $\left(r^{2}=0.8262\right)$

\begin{tabular}{lrrll}
\hline Variable name & \multicolumn{1}{c}{$\beta$-coef } & $F$-ratio & Sign. prob. \\
\hline syndrome $(p)$ & -0.6169 & 315.3 & $* * *$ \\
seed dispersal $(s)$ & 0.4427 & 162.4 & $* * *$ \\
SI-system $(S I)$ & -0.3191 & 84.4 & $* * *$ \\
turnover rate $(t)$ & 0.2745 & 62.4 & $* * *$ \\
$p \times s$ & -0.0680 & 3.8 & $*$ \\
$p \times S I$ & 0.0731 & 4.4 & $*$ \\
$p \times t$ & -0.0713 & 4.2 & $*$ \\
$s \times S I$ & -0.0999 & 8.3 & $* *$ \\
$s \times t$ & 0.1969 & 32.1 & $* * *$ \\
$t \times S I$ & -0.0224 & 0.4 & $\mathrm{~ns}$ \\
$p \times s \times S I$ & 0.0406 & 1.4 & $\mathrm{~ns}$ \\
$p \times s \times t$ & -0.0596 & 2.9 & $\mathrm{~ns}$ \\
$p \times S I \times t$ & -0.0047 & 0.0 & $\mathrm{~ns}$ \\
$s \times S I \times t$ & -0.0334 & 0.9 & $\mathrm{~ns}$ \\
$p \times s \times S I \times t$ & 0.0433 & 1.6 & $\mathrm{~ns}$ \\
\hline
\end{tabular}

ns $=$ not significant

${ }_{*}^{*} p<0.05$.

$* * p<0.01$.

$* * * p<0.001$.

that between $S I$ and $t$ were significant with respect to the level of inbreeding. Third-and fourth-order interactions did not have significant effects. $F$ values in the simulations reached values mainly between 0.05 and 0.25 , representing a moderate to large increase of homozygosity in the populations as a whole. To get an idea of the development of genotypic patches, $F_{r}$ values at the end of the simulation period were calculated (fig. 4) and pictures of two situations were constructed (fig. 5).

The $F_{r}$-curves-every point is an average of 10 simulations-demonstrated that in all situations the loss of heterozygosity in distance classes was smaller when a non-leptokurtic pollen flow caused by the syndrome was assumed, i.e., the protogynygrowth syndrome inhibited the development of "patches". Fig. 5 shows the spatial distributions of genotypes in two situations (7 and 15) which differed only in the syndrome: absent in fig. 5(a), present in Fig. 5(b). In both situations patches developed; the difference in "patchiness" development can easily be seen. The $F_{r}$ values averaged over 10 simulations per situation showed this difference: 0.28 and $0 \cdot 19$ corresponding to figs $5(\mathrm{a})$ and 5(b), respectively, when measureed over a single interplant distance. The presence of the syndrome lowered the "patchiness" of a population is indicated in table 3. SI and turnover rate had no influence, whereas syndrome and seed dispersal had contrasting effects. A striking feature was that
Table $3 F_{r=1}$ values after 100 generations in 16 situations (see figure 4) and the average effects of the introduction of a variable on $F_{r}$ in a simulation (bottom table)

\begin{tabular}{llcc}
\hline Situation & $F_{r=1}$ & Situation & $F_{r=1}$ \\
\hline 1 & 0.22 & 9 & 0.07 \\
2 & $0 \cdot 19$ & 10 & 0.05 \\
3 & 0.39 & 11 & 0.22 \\
4 & $0 \cdot 25$ & 12 & 0.19 \\
5 & 0.20 & 13 & 0.05 \\
6 & $0 \cdot 18$ & 14 & 0.06 \\
7 & 0.28 & 15 & 0.19 \\
8 & 0.26 & 16 & 0.14 \\
$\overline{\Delta p}=-0 \cdot 125 ; \overline{\Delta s}=+0.113 ; \overline{\Delta S I}=-0.028 ; \overline{\Delta t}=+0.028$ \\
\hline
\end{tabular}

large patches (50-100 individuals) could develop but also disappear within about twenty generations (fig. 5(b)).

Another effect shown by the simulations was a decrease in number of SI-alleles. This was reflected in the decrease of the effective number of SI-alleles per plant (the number of SI-alleles available in the pollen cloud around a female flower $=1 / \Sigma_{p_{i}}^{2}$ whereas $p_{i}=$ the frequency of SI-allele $i$ ) after 100 generations and in the increase of the percentage of first pollinations resulting in self-incompatibility reaction (table 4). It is clear, for example, that with the protogyny-growth syndrome $(p=1)$ a plant ended up with between 5 and 12 effective SI-alleles more than without the syndrome $(p=0)$. Since simulations starting with 10 instead of 250 SIalleles were in principle not different, their results were not included in this paper.

Table 4 The effective number of SI-alleles per plant and the percentage of first pollinations resulting in a self-incompatibility reaction (mean \pm standard deviation) for 900 plants in the centre of the simulated population

\begin{tabular}{|c|c|c|c|c|c|}
\hline Generations & $p$ & $s$ & $t$ & $\begin{array}{l}\text { Effective } \\
\text { SI-alleles }\end{array}$ & $\%$ incomp. \\
\hline 100 & $\begin{array}{l}0 \\
1 \\
0 \\
1 \\
0 \\
1 \\
0 \\
1\end{array}$ & $\begin{array}{l}0 \\
0 \\
1 \\
1 \\
0 \\
0 \\
1 \\
1\end{array}$ & $\begin{array}{r}100 \% \\
100 \% \\
100 \% \\
100 \% \\
25 \% \\
25 \% \\
25 \% \\
25 \%\end{array}$ & $\begin{aligned} 11 \cdot 3 & \pm 1 \cdot 9 \\
23 \cdot 2 & \pm 3 \cdot 1 \\
9 \cdot 2 & \pm 1 \cdot 8 \\
16 \cdot 9 & \pm 2 \cdot 0 \\
9 \cdot 9 & \pm 1 \cdot 6 \\
20 \cdot 7 & \pm 2 \cdot 8 \\
7 \cdot 8 & \pm 1 \cdot 5 \\
12 \cdot 5 & \pm 2 \cdot 4\end{aligned}$ & $\begin{aligned} 13 \cdot 6 & \pm 7 \cdot 9 \\
7 \cdot 0 & \pm 4 \cdot 1 \\
19 \cdot 6 & \pm 10 \cdot 1 \\
10 \cdot 0 & \pm 5 \cdot 3 \\
17 \cdot 7 & \pm 9 \cdot 1 \\
8 \cdot 8 & \pm 4 \cdot 5 \\
25 \cdot 0 & \pm 11 \cdot 5 \\
15 \cdot 5 & \pm 8 \cdot 0\end{aligned}$ \\
\hline 0 & $\begin{array}{l}0 \\
1\end{array}$ & $\begin{array}{l}0 \\
0\end{array}$ & $\begin{array}{l}100 \% \\
100 \%\end{array}$ & $\begin{array}{l}21 \cdot 0 \pm 2 \cdot 5 \\
57 \cdot 1 \pm 4 \cdot 5\end{array}$ & $\begin{array}{l}4 \cdot 6 \pm 4 \cdot 5 \\
2 \cdot 0 \pm 1 \cdot 5\end{array}$ \\
\hline
\end{tabular}

$p=$ pollen flow pattern $(0=$ same height, $1=$ different height $)$. $s=$ seed dispersal $(0=$ no dispersal, $1=$ normally distributed dispersal).

$t=$ turnover rate $(100 \%=$ annual species, $25 \%=$ perennial species). 

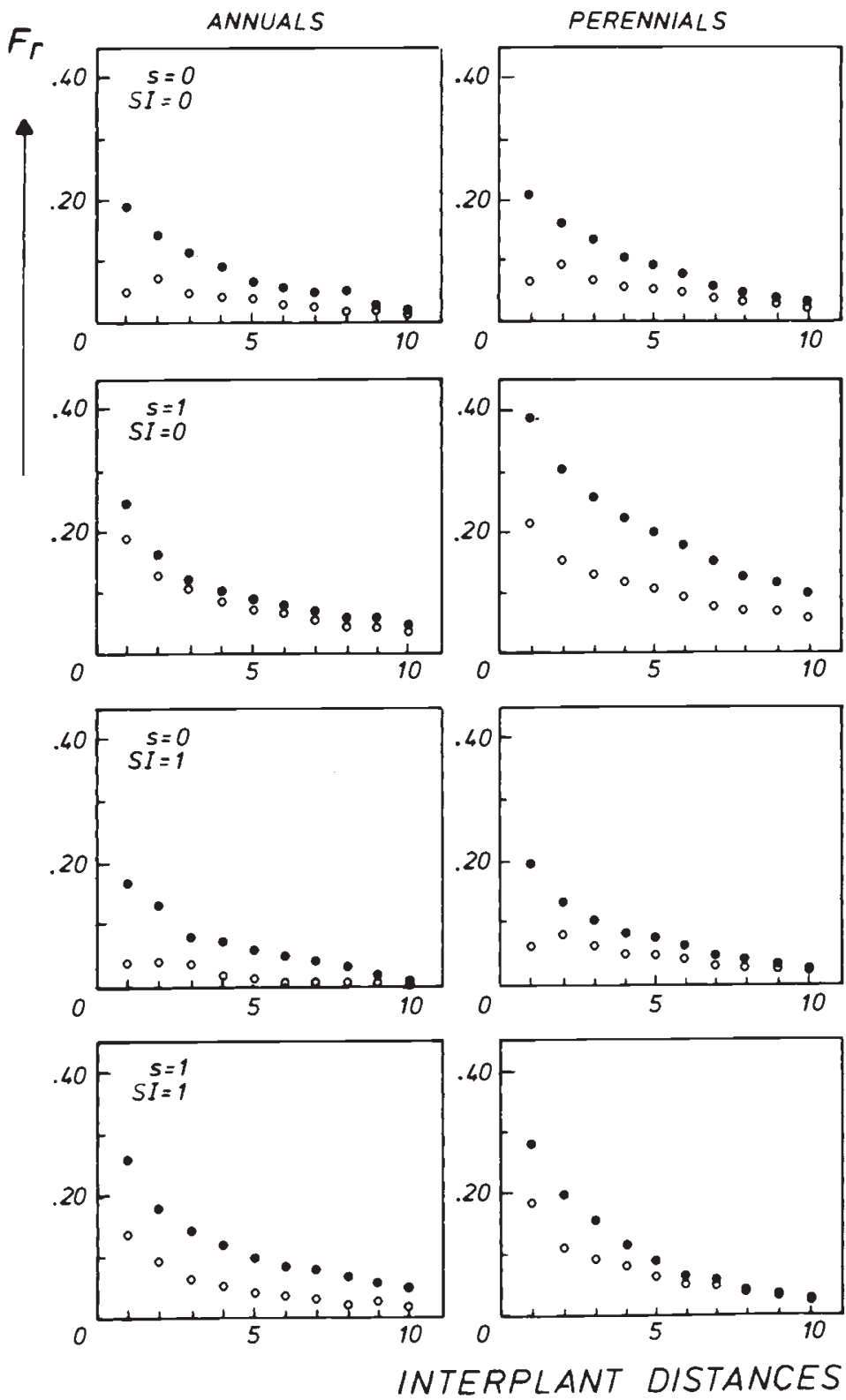

Figure $4 F_{r}$ values at different plant distance units, affected by changed pollen pattern (see legend to fig. 3).

\section{DISCUSSION}

In an earlier paper (Bos et al., 1986) we measured gene flow in a $P$. lanceolata population and argued that in certain conditions restricted gene flow leads to substructuring of the population. In this paper the species $P$. lanceolata serves as an example to describe-among other things-the influence of the reproductive character "protogyny-growth syndrome" on the amount of inbreeding and genetic structure in a simulated population. On account of this syndrome, pollen flow becomes non-leptokurtic (fig. 1). Interestingly, Tonsor (1985) also reports a non-leptokurtic pollen-mediated gene flow in P. lanceolata. He claims this to occur as a result of the clustering of pollen grains. The intermediate-to-large clusters are supposed to contribute disproportionately to the pollen flow pattern. The question remains how generally this clustering occurs in wind-pollinated populations 
(A)

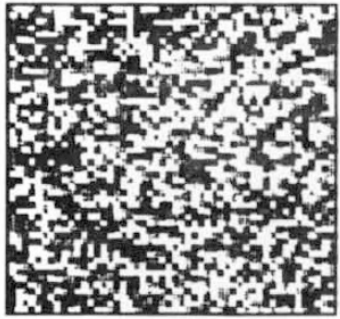

GENERATION 1

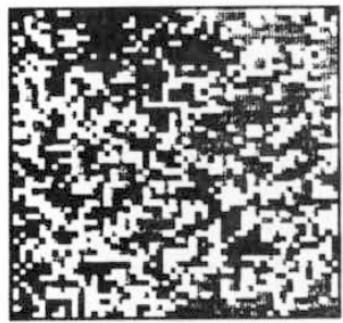

GENERATION 40

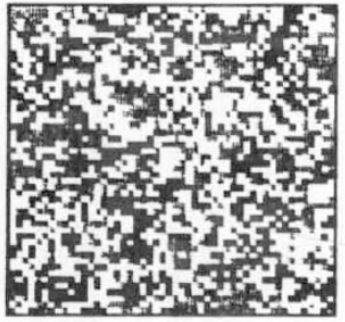

10

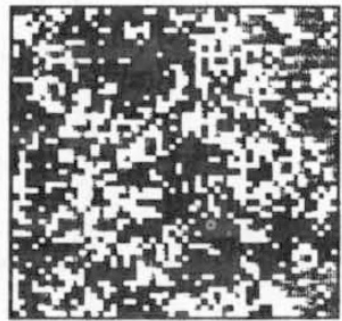

80

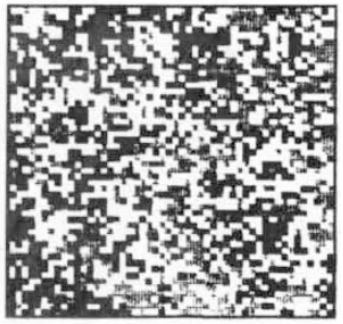

20

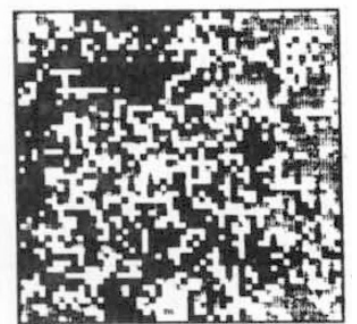

100
(B)

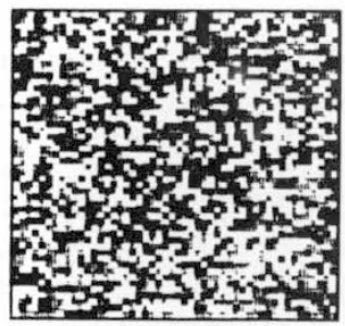

GENERATION 1

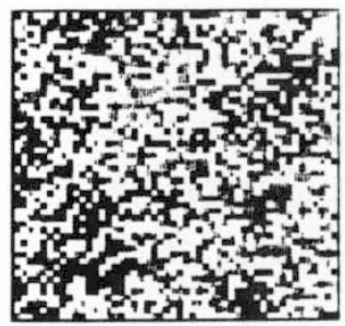

GENERATION 40

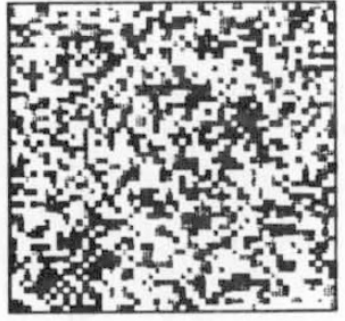

10

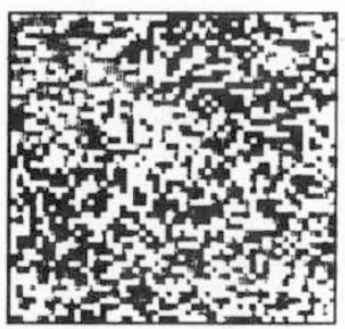

80

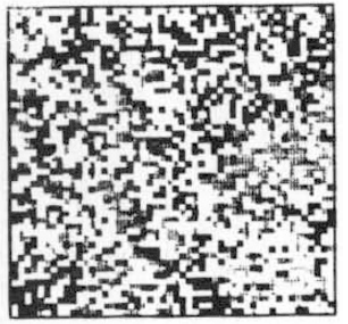

20

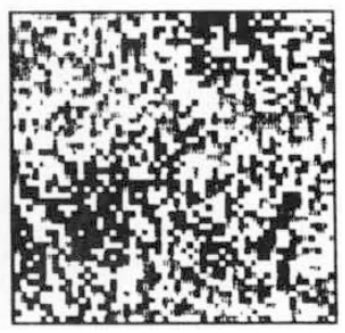

100

Figure 5 Patchy structure changes in time (during 1, 10, 20, 40, 80 and 100 generations). (a) situation 7 without the protogyny-growth syndrome. (b) situation 15 with the syndrome. $\mathbf{\square}$, "AA"; $\square$, "Aa"; $⿴ 囗 十$, "aa".

of $P$. lanceolata, as clustering is observed mainly in insect pollinated populations (Stelleman, 1982). However, Tonsor's hypothesis and the syndrome both have an identical effect on the pollen pattern. The effect of the change from leptokurtic to non- lepiokurtic pollen flow on local inbreeding and therefore on the development of patchy structures within populations is striking. Before discussing this main variable the biological consequences of the effects on the fixation index of the other three 
variables used in this study will be discussed. To prevent misunderstanding: when we are discussing the effects on "inbreeding", we are speaking about the effects on the $F$-value in the populations. The surplus of homozygosity will have more causes than mating between relatives only. It is likely that a second important contribution to $F$ will arise from the bulking of patches with different gene frequencies (Wahlund effect).

\section{The turnover rate}

The most important difference between annual and perennial species lies in the fact that the number and complexity of family relations of neighbouring plants seem to increase greatly in the perennial species when restricted seed dispersal is introduced. This is indicated by the raised level of the $F$ values of these perennial situations as compared to the annual species (compare simulations 4 and 12 with 3 and 11 in fig. 3). The corresponding graphs of fig. 4 show that this resulted in a higher local differentiation ("patchiness") in the perennials, indicated by the higher $F_{r=1}$ values.

\section{Self-incompatibility}

Self-incompatibility clearly suppresses inbreeding, both in annual and in perennial species (fig. 3: compare situations 2 and $6 ; 1$ and 5). In some conditions, however, our gametophytic SI-system still allows a fair amount of inbreeding. This selfincompatibility system depends upon the SI-allele of the pollen grain rather than upon the SIgenotype of the potential male parent as is the case in a sporophytic SI-system (Heslop-Harrison, 1975). Especially when family relations arise between neighbouring plants-as in perennials with restricted seed dispersal, e.g., simulation $7-$ the sporophytic system could be more effective in preventing biparental inbreeding. Local differentiation is hardly affected by the presence of the SI-system because in the case of an incompatible pollination another male parent takes over according to the same pollen flow. In our experiments pollen is never restricted.

The number of SI-alleles has hardly any influence on the level of inbreeding as is revealed by simulations in which the initial number of SIalleles is equal to 10 (not shown in this paper). The effective number of SI-alleles in these simulations ranges between $7 \cdot 2$ and $9 \cdot 0$, which is in principle not different from the values found in simulations started with 250 SI-alleles (table 4).

\section{Seed dispersal}

The situations where a plant is always replaced by one of its offspring show a lower level of inbreeding than when limited seed dispersal takes place (fig. 3 and table 2; effects of $s$ ). This is due to the fact that in the latter situations mating between relatives along the mother line may occur. In a perennial species this effect is even more pronounced $(s \times t$ interaction, table 4) which is caused by the increase in number and complexity of family relations mentioned above. Seed dispersal in the simulations is almost completely limited to the first distance class and only effects the $F_{r}$ values in this distance class (fig. 4).

\section{Protogyny-growth syndrome}

The protogyny-growth syndrome resulting in a non-leptokurtic pollen flow, as opposed to the often found leptokurtic pollen flow (fig. 1), has a highly significant and important effect on the fixation index (table 2). The protogyny-growth syndrome reduces the frequency of nearest neighbour matings: the pollen cloud maximum concentration is beyond the nearest neighbour (fig. 1). The presence of the syndrome can counteract the positive effect of restricted seed dispersal or perenniality (table 2). With the syndrome pollen flow passes the nearest relatives and so effects a decrease in the degree of local inbreeding in the population caused by the limited seed dispersal or perenniality. This lowered biparental inbreeding may be an advantage in a self-incompatible species like $P$. lanceolata, since the number of lethal recessive alleles in an outcrossing species is thought to be considerable (Lande and Schemske, 1985; Schemske and Lande, 1985; Van Damme and Bos, in preparation).

The larger number of potential male parents caused by the protogyny-growth syndrome in wind-pollinated species always results in a lower local differentiation. Mating between relatives will be less likely, resulting in a lower inbreeding coefficient. In simulations of insect-pollinated plants (Turner et al., 1982) using Nearest Neighbour Pollination (NNP) an $F$ value of 0.4 is reached compared with 0.20 in this paper. Their most important conclusion, the significant formation of patches of genetically identical individuals in the absence of selection pressures is confirmed in our simulations. The effects of the variables in our simulations on the "patchiness" are demonstrated by the average effect of the introduction of a variable (table 3). It is amazing to see how 
homozygosity and patch structure evolved in insect pollinated populations solely by the NNP and limited seed dispersal (Turner etal., 1982) and in our simulations of a wind-pollinated species like $P$. lanceolata mainly are influenced by restricted seed dispersal and protogyny-growth syndrome (PGS). NNP and PGS both have their influence on gene flow via pollen flow pattern. NNP restricts pollen flow and PGS increases gene flow. The latter can be seen by comparing mean gene transport values $(M$; Van Dijk, 1987) in situations with and without PGS:

$\begin{array}{rccccccc} & \text { situation } & \text { PGS } & M(\mathrm{~m}) & & \text { situation } & \text { PGS } & M(\mathrm{~m}) \\ 4 & 010 & - & 1.92 & 8 & 011 & - & 2.85 \\ 12 & 110 & + & 2.21 & 16 & 111 & + & 5.26\end{array}$

In the PGS + situations gene flow distances are larger.

Our simulations demonstrate that the protogyny-growth syndrome is a gene flow character that even in a situation without selection pressures can influence the evolution of patch structure in populations of a plant species like $P$. lanceolata. A striking difference compared with the outcome of insect Nearest Neighbour Pollination (Turner et al., 1982) is, that in our simulations large patches had a more restricted life time, probably resulting from the larger gene flow in our situations (fig. 1).

Acknowledgements Our special thanks are due to Henk Mulder for drawing the figures, to Saskia Walburgh Schmidt and Joke Poelstra for careful preparation of the manuscript and to Drs Van Delden, Van Damme, Van Dijk and Hoekstra for helpful comments on the manuscript.

\section{REFERENCES}

ANTONOvicS, J. 1968. Evolution in closely adjacent plant populations. V. Evolution of self-fertility. Heredity, 23, 219-238.

ARASU, N. T. 1968. Self-incompatibility in Angiosperms: Annual Review Genetics, 39, 1-24.

BOS, M., HARMENS, H. AND VRIELING, K. 1986. Gene flow in Plantago. I, Gene flow and neighbourhood size in $P$. lanceolata. Heredity, 56, 43-54.

BOS, M., STEEN, R. AND haRMens, H. 1985. Protogyny in Plantago lanceolata populations: an adaption to pollination by wind? In Jacquard, P. et al. (eds) NATO ASI Series, vol. G5, Springer-Verlag, Berlin Heidelberg, pp. 327-337.

BRADSHAW, A. D. 1972. Some evolutionary consequences of being a plant. Evol. Biol. 5, 25-47.

CAHALAN, C. M. AND GLIDDON, C. 1985. Genetic neighbourhood size in Primula vulgaris. Heredity, 54, 65-70.

CHRISTIANSEN, F. B. 1975. Hard and soft selection in a subdivided population. Am. Nat., 109, 11-16.

CRAWFORD, T. J. 1984. What is a population? In Shorrocks, B. (ed.) Evolutionary Ecology, Blackwell Scientific Publications, Oxford, pp. 135-173.
ELLSTRAND, N. C. AND MARSHALL, D. L. 1985. Interpopulation gene flow by pollen in wild radish, Raphanus sativus. Am. Nat., 126, 606-616.

ENDLER, J. A. 1973. Gene flow and population differentiation. Science, 179, 243-250.

ENNOS, R. A. 1985. The mating system and genetic structure in a perennial grass, Cynosurus cristatus L. Heredity, 55, 121126.

ENNOS, R. A. AND CLEGG, M. T. 1982. Effect of population substructuring on estimates of outcrossing rate in plant populations. Heredity, 48, 283-292.

GILlESPIE, J. H. 1975. The role of migration in the genetic structure of populations in temporally and spatially varying environments. I. Conditions for polymorphism. Am. Nat., $109,127-135$.

GLIDdON, C., BELhassen, E. AND GOUYON, P-H. 1987. Genetic neighbourhoods in plants with diverse systems of mating and different patterns of growth. Heredity, 59, 29. 32.

HANDEL, S. N. 1982. Dynamics of gene flow in an experimental garden of Cucumis melo (Cucurbitaceae). Am. J. Bot., 69, 1538-1546.

HANDEL, S. N. 1983. Contrasting gene flow patterns and genetic subdivision in adjacent populations of Cucumis sativus (Cucurbitaceae). Evolution, 37, 760-771.

HESLOP-HARRISON, J. 1975. Incompatibility and the pollenstigma interaction. Annu. Rev. Plant Physiol., 26, 403-425

JAIN, S. K. AND BRADSHAW, A. D. 1966. Evolutionary divergence among adjacent plant populations I the evidence and its theoretical analysis. Heredity, 21, 407-441.

KIMURA, M. AND WEISS, G. 1964. The stepping stone model of population stucture and the decrease of genetic correlation with distance. Genetics, 49, 561-576.

LANDE, R. AND SCHEMSKE, D. W. 1985. The evolution of self-fertilization and inbreeding depression in plants. I. Genetic models. Evolution, 39, 24-40.

LEVIN, D. A. 1981. Dispersal versus gene flow in plants. Annu. Missouri Bot. Gard., 68, 233-253.

LEVIN, D. A. 1984. Immigration in plants: an exercise in the subjunctive. In Dirzo, R. and Sarukhun, J. (eds) Perspectives on Plant Population Ecology, Sinauer, Sunderland, Mass.

LEVIN, D. A. AND KERSTER, H. W. 1971. Neighbourhood structure in plants under diverse reproductive methods. Am. Nat., 105, 345-354.

LEVIN, D. A. AND KERSTER, H. W. 1974. Gene flow in seed plants. Evol. Biol., 7, 139-220.

LEVIN, D. A. AND WILSON, J. B. 1978. The genetic implications of ecological adaptions in plants. In Freysen, A. H. J. and Woldendorp, J. W. (eds) Structure and Functioning of Plant Populations, North-Holland Publ. Cy., Amsterdam, pp. 75-100.

LLOYD, D. G. AND WEBB, C. J. 1986. The evidence of interference between the presentation of pollen and stigmas in Angiosperms. I, Dichogamy. NZ. J. Bot., 24, 135-162.

MORAN, P. A. P. 1962. The Statistical Processes of Evolutionary Theory. Clarendon Press, Oxford.

NEI, M., Chakravarti, A. AND TAteno, Y. 1977. Mean and variances of $F_{S T}$ in a finite number of completely isolated populations. Theor. Popul. Biol, 11, 291-306.

NICHOLLS, M. S. 1985. Pollen flow, population composition, and the adaptive significance of distyly in Linum tenuifolium (Linaceae). Biol. J. Linn. Soc., 25, 235-242.

PRICE, M. V. AND WASER, N. M. 1979. Pollen dispersal and optimal outcrossing in Delephinium nelsoni. Nature, 277, 294-296.

ROHLF, F. J. AND SCHNELL, G. D. 1971. An investigation of the isolation by distance model. Am. Nat., 105, 295-324. 
Roughgarden, J. 1979. Theory of Population Genetics and Evolutionary Ecology: An Introduction. Macmillan, NY.

SCHAAL, B. A. 1975. Population structure and local differentiation in Liatris cylindracea. Am. Nat., 109, 511-528.

SCHAAL, B. A. 1980. Measurement of gene flow in Lupinus texensis. Nature, 284, 450-451.

SCHEMSKE, D. W. AND LANDE, R. 1985. The evolution of self-fertilization and inbreeding depression in plants. II. Empirical observations. Evolution, 39, 41-52.

SCHMITT, J., EHRHARDT, D. AND SWARTZ, D. 1985. Differential dispersal of self-fertilized and outcrossed progeny in jewelweed (Impatiens capensis). Am. Nat., 126, 570-575.

Stelleman, P. 1982. De Betekenis van de Biotische Bestuiving bij Plantago lanceolata. Thesis, G.U. Amsterdam.

SUTTON, O. G. 1953. The atmosphere in motion. II. Turbulent flow. In Micrometeorology, McGraw-Hill Company.

TONSOR, S. J. 1985. Intrapopulational variation in pollen-mediated gene flow in Plantago lanceolata L. Evolution, 39, 775-783.

TSUKADO, M. 1982. Pseudotsuga menziesii (Mirb) Franco: Its pollen dispersal and late quarternary History in the Pacific northwest. Jpn. J. Ecol., 32, 159-187.
TURNER, M. E., STEPHENS, J. C. AND ANDERSON, W. W. 1982. Homozygosity and patch structure in plant populations as a result of nearest-neighbor pollination. Proc. Nat. Acad. Sci., 79, 203-207.

VAN DAMME, J. M. M. AND BOS, M. Genetic load in selfincompatible Plantago lanceolata (in preparation).

VAN DIJK, H. 1987. A method for the estimation of gene flow parameters from a population structure caused by restricted gene flow and genetic drift. Theor. Appl. Genet., 73, 724736.

WADDINGTON, K. D. 1983. Pollen flow and optimal outcrossing distance. Am. Nat., 122, 147-151.

WEISS, G. AND KIMURA, M. 1965. A mathematical analysis of the stepping stone model of genetic correlation. J. Appl. Probab., 2, 129-149.

WRIGHT, S. 1951. The genetical structure of populations. Annu. Eugen., 15, 323-354

WRIGHT, S. 1968. Evolution and the Genetics of Populations. I. Genetic and Biometric Foundations. University of Chicago Press, Chicago. 